\title{
Condom social marketing program to prevent HIV/AIDS in post- conflict Liberia
}

Harris $\mathrm{AO}^{1}$, Jubwe $\mathrm{S}^{1,2}$, Kennedy $\mathrm{SB}^{1,3}$, Taylor $\mathrm{CH}^{1}$, Martin $\mathrm{RB}^{1}$, Bee EM${ }^{1}$, Perry OS ${ }^{1}$, Massaquoi MT ${ }^{1}$, Woods DV ${ }^{1}$, Barbu $\mathrm{EM}^{1}$

1. UL-PIRE Africa Center, An HIV/STD Prevention Research Center, University of Liberia, Monrovia, Liberia

2. Department of Sociology \& Anthropology, College of Liberal Arts, University of Liberia, Monrovia, Liberia

3. Pacific Institute for Research \& Evaluation (PIRE), Louisville Center, 1300 South Fourth Street, Suite 300, Louisville, KY 40208, USA

\begin{abstract} behaviors among high risk adolescents in post-conflict environments. businesses to support this endeavor. post-conflict country. city of Liberia.

African Health Sciences 2011; 11(S1): S77 - S81

\section{Introduction}

The commonest mode for HIV/STI transmission in sub-Saharan Africa is heterosexual activity ${ }^{1-8}$. Nevertheless, effective condom use remains a significant public health challenge ${ }^{9-12}$. As Liberia emerges from over a decade of civil war with a health infrastructure that has been destroyed, available data revealed that youths engage in risky sexual behaviors $^{7-8,13}$. Even though condoms are dispensed by community-based organizations (CBOs) and public health facilities, significant gaps exist regarding their accessibility and availability, especially for mobile and transient populations such as youths, commercial sex workers (CSW) and men who have sex with men (MSM).
\end{abstract}

Background: Youths in sub-Saharan Africa (SSA) account for a large burden of the global HIV/STI crises. As such, strategies directed at promoting behavioral modifications would be critical to reducing the prevalence of risky sexual

Objectives: This study describes a condom promotion strategy to prevent HIV/STIs among highly vulnerable urban youth in a post-conflict, resource-constrained environment via the provision of both male and female condoms to nontraditional venues like music and photo shops, ice cream parlors, money exchange centers and beauty salons.

Methods: Community members in the designated catchment areas volunteered their services and the use of their small

Results: In this paper, we describe the condom promotion strategy and its implications within the context of a communitybased participatory social marketing program to prevent risky sexual behaviors among highly vulnerable urban youth in a

Conclusion: We postulate that this approach may likely increase condom use among urban youth in Monrovia, the capital

Keywords: Condom Social Marketing, Post-Conflict Liberia, HIV/STI Prevention

\begin{tabular}{l}
\hline * Correspondence author \\
Stephen B. Kennedy \\
Pacific Institute for Research \& Evaluation (PIRE) \\
Louisville Center \\
1300 South Fourth Street, Suite 300 \\
Louisville, KY 40208 , USA \\
Tel: 5026343694 ext. 7332 \\
Fax: 5026345690 \\
E-mail: kennedy@pire.org
\end{tabular}

African Health Sciences Vol 11 Special Issue 1 August 2011
At the community levels, structured condom social marketing activities do not exist. Although national data are limited, HIV seroprevalence is estimated to be $5.7 \%$ among pregnant women ${ }^{14}$ and $1.5 \%$ for the general population, with the urban rates twice the rates of the rural areas ${ }^{15}$. Moreover, STIs are rapidly increasing among young people, especially females, as a result of socio-economic disparity, sexual violence, gender inequality, commercial sex, and substance use $\mathrm{e}^{7-8,13-14}$. However, local data are unavailable to better describe the impact that these variables may have on HIV/ STI transmission patterns.

Although reports from the National AIDS/ STI Control Program (NACP) of the Ministry of Health \& Social Welfare (MOHSW) indicate that condom use is gradually increasing among people in heterosexual relationships, its use remains relatively low $^{13}$. In this report, we highlight efforts to promote condom via a community-based participatory process to prevent HIV/STIs among urban youth in Monrovia, the capital city of Liberia. 


\section{Methods \\ Overview}

We were implementing a five-year communitybased intervention trial to adapt, administer and evaluate a proven behavioral-driven HIV/STI prevention program among urban youth aged 1517 years in post-conflict Liberia. Since the program had increased condom use up to 12 months after it ended among urban youth in a prior study ${ }^{16-18}$, we hypothesized that an effectively designed social marketing initiative would promote condom use among our target population.

\section{Demographic characteristics}

The study setting, Montserrado county, which includes Monrovia, is one of 15 political subdivisions in Liberia. Youth under age 20 account for about half of the population with nearly equal proportions of males and females. While there are 16 tribal groups, our project setting is an ethnically mixed region where people communicate in English, the country's official language ${ }^{13}$. Since religion shapes one's attitudes and perceptions of social issues ${ }^{13}$, religious members are least likely to support condom promotion and more likely to support abstinence until marriage. Therefore, religion was not an exclusion criterion.

The study methods and procedures were approved by the institutional review boards (IRBs) of the Pacific Institute for Research \& Evaluation (PIRE) in the United States (U.S.) and the University of Liberia (UL) in Monrovia, Liberia, respectively.

\section{Recruitment of condom distribution sites}

Based on needs assessment, Monrovia was demarcated into four zones to (1) minimize contamination; (2) minimize logistical challenges; and (3) identify potential sites for speaking engagements and condom distribution. In each zone, suitable venues were identified based on, for example, proximity to surrounding neighborhoods, schools, markets, and/or recreational centers. Formal contacts were then initiated with each potential site owner/ proprietor to elicit their respective interests and commitments to the goals of the project, and contact information was obtained for future follow-ups.

We identified 106 potential condom distribution sites within the four zones of which 88 $(83 \%)$ agreed and $18(17 \%)$ refused to participate. The high retention rate $(83 \%)$ may have been due to the involvement of thecommunity and the establishment of a community advisory board (CAB) to serve as a liaison between the project and community organizations. Reasons provided for refusals by $17 \%$ (18) of potential sites included a lack of interest in participating in condom distribution, pre-occupation with other business activities, and conflict with religious beliefs.

The sites included diverse businesses such as music shops, video recording studios, photo shops, CD-ROM and DVD disc rental shops, grocery stores, beauty salons, computer service centers, ice cream parlors, entertainment centers, barber shops, money exchange centers, etc.

\section{Building condom knowledge \& skills of community distributors}

A representative per ecah site was invited to one of three identical one-day training workshops regarding their roles and responsibilities. Each workshop covered the following topics:

(1) Importance of condoms

(2) Privacy/confidentiality

(3) Condom demonstration skills

(4) Principles of condom social marketing

(5) Beneficiaries of condoms

(6) Condom supply chain mechanism and documentation.

Each workshop, lasting for 3-4 hours with refreshments served, was moderated by trained program staff. At the conclusion, each business owner was provided copies of all training materials, samples of condom distribution and replenishment logs, and reimbursed their transportation costs. Except for souvenirs and flyers, no financial incentives were provided to participants.

Ninety representatives from 88 sites completed the condom distributor training program. Two sites from zone four sent two additional male representatives. Of those participants, 63 (70\%) were males and 27 (30\%) females. By sessions, 34 (38\%) attended the first (21 males, 13 females), $32(36 \%)$ the second (23 males, 9 females) and $24(27 \%)$ the third (19 males, 5 females).

During the workshops, significant levels of enthusiasm were exhibited by participants, wherein a wide range of concerns were raised. They included: (1) the legal ramifications for providing condoms to minors, (2) whether condom distributors with limited knowledge on safer sex issues were qualified to counsel youth on HIV/STIs, (3) the need to use print and broadcast media to promote the project, (4) the need to provide incentives to condom distributors, (5) the issuance of condoms to individuals from communities not linked to a 
condom distribution site, (6) the rationale for targeting youth rather than adults, and (7) the perceived relationship between condom use and population growth. For some participants, this was the first opportunity to have seen and/or heard about female condoms. Concerns raised by participants during the administration of the sessions were addressed by the program facilitators. The facilitations of the condom skill building training sessions were very interactive and participatory, and verbal exchanges were cordial during the thematic discussions.

At the end, a female representative from zone one withdrew due to concerns regarding condom distribution at her business center, which conflicted with her religious beliefs. Accordingly, 87 businesses from four zones were enrolled in our condom social marketing project (See Table 1). By gender $61(70 \%)$ representatives were males (excluding the two additional males from zone four who attended the workshops) and $26(30 \%)$ females (excluding the female who withdrew her business).

\section{Monitoring and sustaining a condom social marketing program}

Bi-monthly monitoring visits to condom distribution sites will be conducted by program staff as part of the study's process evaluation. Also, structured questions on participant's surveys regarding condom knowledge and attitude, availability and accessibility, carrying (e.g., preparatory behavior), self-efficacy, and staging (e.g., pre-contemplation) will be incorporated into the study's outcome evaluation. These data will be collected at structured intervals of up to 12months to provide information regarding the potential benefits of the proposed condom social marketing program.

\section{Results \\ Community-based condom distribution initiative}

On average, we dispensed about $225-250$ pieces of male and 3-5 pieces of female condoms semimonthly per site. The business owners/proprietors were provided standardized supply chain documentation forms containing information regarding the dates and quantities of condoms issued, and the genders of study participants and community members requesting condoms, etc. To prevent data collection errors by business owners, different supply chain documentation forms were developed for youth and community members.

Table 1: Condom distribution sites by zones, gender of participants, and types of condoms issued

\begin{tabular}{|c|c|c|c|c|c|c|c|c|c|}
\hline \multirow[t]{2}{*}{ Zones } & \multirow[t]{2}{*}{$\begin{array}{l}\text { Eligible Number of } \\
\text { consenting condom } \\
\text { distribution sites }\end{array}$} & \multicolumn{3}{|c|}{$\begin{array}{l}\text { Workshop attendance } \\
\text { m by number of } \\
\text { condom distribution } \\
\text { sites \& gender of site } \\
\text { representatives* }\end{array}$} & \multicolumn{3}{|c|}{$\begin{array}{l}\text { Final number of } \\
\text { enrolled } \\
\text { condom distribution } \\
\text { sites*** }\end{array}$} & \multicolumn{2}{|c|}{$\begin{array}{l}\text { Types of condoms } \\
\text { issues**** }\end{array}$} \\
\hline & & Sites & Males** & $\overline{\text { Females }}$ & Site & Male & Females & $\begin{array}{l}\text { Male } \\
\text { condoms }\end{array}$ & $\begin{array}{l}\text { Female } \\
\text { condoms }\end{array}$ \\
\hline 1 & 16 & 14 & 9 & 5 & 13 & 9 & 4 & 6,000 & 72 \\
\hline 2 & 33 & 28 & 18 & 10 & 28 & 18 & 10 & 5,600 & 56 \\
\hline 3 & 20 & 17 & 14 & 3 & 17 & 14 & 3 & 3,200 & 32 \\
\hline 4 & 37 & 29 & 22 & 9 & 29 & 20 & 9 & 5,600 & 156 \\
\hline Total & 106 & 88 & 63 & 27 & 87 & 61 & 26 & 20,400 & 316 \\
\hline
\end{tabular}

*The total number of male and female representatives from consenting condom distribution sites who attended the workshop was 90 participants.

**Two male participants, instead of one per site, represented two different sites from zone IV. Accordingly, there were 90 participants representing 88 sites.

*** One site, with a female representative from zone 1, withdrew after the workshop due to religious concerns regarding condom distributions on her business premises. So, the total number of condom distribution sites enrolled into the study was 87 sites.

${ }^{* * * *}$ Condoms Issued: Total number (or pieces) of male and female condoms distributed. 
The quantities of condoms issued to the condom distribution sites by zones were: 6,000 male and 72 female condoms to zone one; 5,600 male and 56 female condoms to zone two; 3,200 male and 32 female condoms to zone three; and 5,600 male and 156 female condoms to zone 4. Overall, 20,400 male and 316 female condoms were distributed to 87 sites for this report.

\section{Discussion}

Community involvement in program implementation The strategy employed by this project to promote condoms at the community-level was embraced by community members. The fact that community members had volunteered their business centers to distribute condoms at no cost is also indicative of their buy-in to the project and their desire to proactively assist in the mitigation of $\mathrm{HIV} / \mathrm{STIs}$. In addition, the disparity in the quantities of male and female condoms distributed to business sites was due to, for example:

(1) lack of knowledge and/or awareness about female condoms;

(2) low usage rate of female condoms;

(3) inaccessibility to female condoms; and

(4) cultural concerns regarding a perceived relationship between female condoms and sexual promiscuity. Furthermore, initial concerns raised by community members, such as privacy and the legality of providing condoms to minors, gradually subsided and condom distribution sites became more visible and accessible to our populations.

\section{Program implementation challenges in a post-conflict environment}

There were some challenges. One major challenge faced by the project was logistical concern regarding the continual supply of condoms due to continual lack of condoms from our distributors to meet the increasing demands. Another challenge was a request by distributors to provide incentives and transportation reimbursement to community volunteers. There is a significant need for additional training workshops to address, for example, condom use myths, pros and cons for condom use, condom breakage/slippage, and its effectiveness in HIV/ STI prevention, etc.

Since condom social marketing is a new public health innovation in post-conflict Liberia, motivating community volunteers to implement this project without financial incentives is gradually emerging as a significant community-level barrier due to the socioeconomic situation in the country. Liberia is presently in a post-conflict transition where the socio-economic systems and health infrastructures had collapsed ${ }^{8-9,13-14,19}$. While these contexts are beyond the scope of this paper, structural factors such as high rates of unemployment fuel high risk behaviors ${ }^{8-}$ 9,13-14. We believe that the effective outcome of this project may influence community members to develop a sustainable plan. Sustainability, for our purpose, is defined as the process of ensuring that an effective innovation is integrated into the ongoing operations of communities with buy-in by stakeholders ${ }^{8,20}$. First, it is desirable to have sustainable partnership. Second, an action plan to sustain the desired initiative needs to take place. Third, the desired initiative needs to be integrated into the normal operating system of the communities. Lastly, such a sustainability strategy assumes a five-step process (assessment, development, implementation, evaluation, and reassessment and modification) to create an acceptable level of readiness to sustain effective innovations. It also incorporates a process of monitoring the extent to which the innovation continues to benefit the targeted communities.

Most importantly, we believe that an effective sexual risk reduction program should aim to increase the use of condoms among individuals at high risk for HIV/ STIs ${ }^{2,21-26}$. Therefore, this program has been relatively successful in mobilizing community members, via a participatory mechanism, to take relevant public health actions regarding the need to prevent HIV/STIs within their respective communities. It has also increased the perceived intention of community members to think about formulating preliminary social marketing plans. Such a community generated sustainability plan has the potential to be effective in promoting safer sexual behaviors. .

This project has the potential to make condoms readily available and accessible to a larger segment of underserved urban communities in post-conflict Liberia. To date, preliminary observations indicate that the provision of condoms at no cost to study participants and community members has begun to provide perceived relief to members of the targeted communities. This project clearly demonstrates that the implementation of a condom social marketing initiative is feasible in a post-conflict, resourceconstrained setting like Liberia where high risk behavior ${ }^{7}$ $8,13-14,19$ is a major public health concern for the country's health system.

This is the first published report of a structured condom social marketing program in post-conflict Liberia. Our expectation is that by disseminating our field experiences, efficacy and lessons learned with stakeholders, it may garner the needed support to sustain this crucial public health initiative and create a potential avenue for additional research by health service-based organizations to validate our findings.

\section{Conclusion}

Even though we present the preliminary results from the analyses of the baseline process data, we postulate that this approach may likely increase condom use among urban youth in Monrovia, the capital city of Liberia. In addition, we anticipate that other targeted studies will be conducted by international researchers to examine the determinants of high-risk sexual behaviors among high risk communitybased adolescents in post-conflict settings in order to guide the implementation of evidence-based HIV/STI prevention programs and policies. 


\section{Acknowledgment}

This study was funded by a grant [R01 HD 045133] from the National Institute of Child Health and Human Development (NICHD) of the National Institutes of Health (NIH) in Bethesda, Maryland, USA.

\section{References}

1. Centers for Disease Control and Prevention. HIV/ AIDS Surveillance Report: Cases of HIV infection and AIDS in the United States 2002;11. Department of Health and Human Service, Atlanta, GA.

2. Noar SM, Cole C, Carlyle K. Condom use measurement in 56 studies of sexual risk behavior: review and recommendations. Arch Sex Behav. 2006;35(3):327-45.

3. Yarber WL, Milhausen RR, Crosby RA, et al. Public opinion about condoms for HIV and STD prevention: a Midwestern state telephone survey. Perspect Sex Reprod Health. 2005;37(3):148-54.

4. Thompson SC, Kyle D, Swan J, et al. Increasing condom use by undermining perceived invulnerability to HIV. AIDS Educ Prev. 2002;14(6):505-14

5. Kennedy SB. Massaquoi MBF. Heterosexual HIV Transmission In Africa: Recent Findings \& Future Directions. International Journal of STD \& AIDS 2003;14(6);428.

6. Hester R. Kennedy SB. Candida Infection as risk factor for HIV.J Women Health 2003;12(5):487-495.

7. Kennedy SB, Johnson K, Harris AO, et al. Evaluation of HIV / AIDS prevention resources in Liberia: strategy and implications. AIDS Patient Care STDS. 2004;18(3):169-80.

8. Johnson K, Kennedy SB, Harris AO, et al. Strengthening the HIV/AIDS service delivery system in Liberia: an international research capacity-building strategy. J Eval Clin Pract. 2005;11(3):257-73.

9. Kennedy, SB, Nolen S, Applewhite J, et al. A Quantitative Study on Condom Behaviors of 18-24 Years African American Males. AIDS Patient Care \& STDs. 2007; 21(5):306-320.

10. Kennedy SB, Nolen S, Applewhite J, et al. Condom Use Behaviors of 18-24 Year-Old Urban African American Males: A Qualitative Study. AIDS Care. 2007;19(8):1032-1038.

11. Kennedy SB, Nolen S, Applewhite J, et al. A Qualitative Study on Urban African American Males' Perceptions About Condom Use, Gender and Power, and Prevention Program. Journal National Medical Association. 2007;99(12):1395-1401.

12. Norris AE, Phillips RE, Statton MA, et al. Condom use by male, enlisted, deployed navy personnel with multiple partners. Mil Med. 2005;170(10):898-904.

13. Ministry of Planning \& Economic Affairs (MPEA), University of Liberia (UL) \& United Nations Population Fund (UNFPA). Liberia demographic and health survey (LDHS): Analytical Report, 1999/2000;3. Monrovia, Liberia.
14. National AIDS/STD Control Program (NACP), Ministry of Health \& Social Welfare (MOHSW) of the Republic of Liberia, World Health Organization (WHO), Global Fund to Fight AIDS, Tuberculosis \& Malaria (GFATM)/United Nations Development Program (UNDP). HIV sentinel survey among pregnant women attending antenatal care, 2006. Monrovia, Liberia.

15. Ministry of Planning \& Economic Affairs (MPEA) \& United States Agency for International Development (USAID), United Nations Population Fund (UNFPA). Liberia demographic and health survey (LDHS): Preliminary Report, 2007. Monrovia, Liberia.

16. Bandura A. Social foundations of thought and actions: A social cognitive theory. Englewood, NJ: Prentice Hall, 1986.

17. Prochaska JO, DiClemente CC, Norcross JC. In search of how people change. Applications to addictive behaviors. Am Psychol. 1992;47(9):1102-14.

18. Jemmott JB 3rd, Jemmott LS, Fong GT. Abstinence and safer sex HIV risk-reduction interventions for African American adolescents: a randomized controlled trial. JAMA. 1998;279(19):1529-36.

19. Kennedy SB, Harris AO, Oudemans E, et al. Developing Capacity To Protect Human Research Subjects In A Post-Conflict, Resource-Constrained Setting: Procedures \& Prospects. J Med Ethics. 2006;32(10):592-595.

20. Johnson KW, Hays C, Center H, et al. Building capacity and sustainable prevention innovations: A sustainability planning model. Evaluation and Program Planning. 2004; 27, 135-149

21. Crosby RA, DiClemente RJ, Wingood GM, et al. Identification of strategies for promoting condom use: a prospective analysis of high-risk African American female teens. Prev Sci. 2003;4(4):263-70.

22. Anderson JE. Condom use and HIV risk among US adults. Am J Public Health. 2003;93(6):912-4.

23. Francis DP, Chin J. The prevention of acquired immunodeficiency syndrome in the United States. An objective strategy for medicine, public health, business, and the community. JAMA. 1987;257(10):1357-66.

24. DiClemente RJ, Lodico M, Grinstead OA, et al. AfricanAmerican adolescents residing in high-risk urban environments do use condoms: correlates and predictors of condom use among adolescents in public housing developments. Pediatrics. 1996;98(2 Pt 1):26978.

25. Stone KM, Timyan J, Thomsa EL. Barrier methods for the prevention of sexually transmitted diseases. In KK. Holmes, PF. Sparling, P. Maardh, SM. Lemon, WE. Stamm, P. Piot, \& JN. Wasserheit (Eds.). Sexually Transmitted Diseases, pp. 1307-1322, 1999.

26. Ao T, Sam N, Manongi R, et al. Social and behavioural determinants of consistent condom use among hotel and bar workers in Northern Tanzania. Int J STD AIDS. 2003;14(10):688-96. 